\title{
Atividade biológica percebida e indicadores edáficos em uma área de fruticultura periurbana
}

A produção agrícola em áreas urbanizadas promove a segurança alimentar e presta importantes serviços ecossistêmicos. Portanto, este estudo objetivou caracterizar a atividade biológica e os parâmetros edáficos, buscando relacionar as condições físicas e biológicas do solo. $\mathrm{O}$ estudo foi realizado em uma área de fruticultura periurbana. O levantamento da diversidade biológica foi realizado pela avaliação visual da presença de atividade biológica, cobertura vegetal, fungos, bioturbação e raízes, utilizando uma estrutura reticulada de $0,5 \mathrm{~m}^{2}$, subdividida em quadrantes de $0,05 \times 0,05 \mathrm{~m}$. Os parâmetros de solo analisados foram a resistência do solo a penetração, matéria orgânica, umidade, peso específico aparente seco, índice de vazios e porosidade. A cobertura sobre a superfície fo estimada por meio de classificação automática de imagens fotográficas. Medidas conservacionistas como a cobertura do solo com palhada, promoveram a manutenção da umidade, a proteção contra o potencial erosivo, o desenvolvimento da diversidade biológica e a produção de matéria orgânica. A análise da atividade biológica percebida pode ser usada como um indicador de qualidade dos solos, relacionando-se com maiores teores de matéria orgânica e porosidade. As áreas com maior resistência do solo a penetração foram aquelas com mais baixos teores de matéria orgânica, menor porosidade e atividade biológica.

\section{Perceived biological activity and edhatic indicators in a periurban orcharding area}

\begin{abstract}
Agricultural production in urbanized areas assists with food security and provides important ecosystem services. Therefore, this study aimed to characterize the biological activity and soil parameters, correlating the physical and biological conditions of the soil. The study was conducted in a periurban orcharding area. The biological diversity was evaluated by visual assessment of the presence of biological activity, vegetation cover, fungi, bioturbation and roots, using a $0.5 \mathrm{~m}^{2}$ reticulated structure, subdivided into quadrants of $0.05 \times 0.05 \mathrm{~m}$. The soil parameters analyzed were soil resistance to penetration, organic matter, moisture, apparent dry specific weight, voids index and porosity. Surface coverage was estimated by automatic classification of photographic images. Conservation measures such as mulching have promoted moisture maintenance, protection against erosion potential, development of biological diversity and production of organic matter. Analysis of perceived biological activity can be used as an indicator of soil quality, relating to higher levels of organic matter and porosity. The areas with the highest soil penetration resistance were those with the lowest organic matter content, lower porosity and biological activity.
\end{abstract}

Keywords: Ecosystem service; Landscape; Macrofauna; Soil management.

Topic: Ciências do Solo

Reviewed anonymously in the process of blind peer.
Received: 06/03/2021 Approved: 22/03/2021
Jocy Ana Paixão de Sousa (iD

Universidade Estadual Paulista Júlio de Mesquita Filho, Brasil http://lattes.cnpq.br/3764134703973551 http://orcid.org/0000-0003-0937-786X

jocy belem@hotmail.com

José Carlos de Souza (in

Universidade Estadual de Goiás, Brasil

http://lattes.cnpq.br/2778060526444090

http://orcid.org/0000-0001-9760-6559

jose.souza@ueg.br

Bruno Paes de Carli (it)

Universidade Estadual Paulista Júlio de Mesquita Filho, Brasil http://lattes.cnpq.br/5116609174003319

http://orcid.org/0000-0002-0836-1244

bpdecarli@yahoo.com.br

\author{
Felipe Hashimoto Fengler (iD) \\ Universidade Estadual Paulista Júlio de Mesquita Filho, Brasi \\ http://lattes.cnpq.br/9505291064775154 \\ http://orcid.org/0000-0002-7982-2300 \\ felipe fengler@hotmail.com \\ Gerson Araújo de Medeiros (iD \\ Universidade Estadual Paulista Júlio de Mesquita Filho, Brasil \\ http://lattes.cnpq.br/8657413561406750 \\ http://orcid.org/0000-0002-9122-3909 \\ gerson.medeiros@unesp.br \\ Admilson Írio Ribeiro \\ Universidade Estadual Paulista Júlio de Mesquita Filho, Brasil \\ http://lattes.cnpq.br/5907913107550684 \\ http://orcid.org/0000-0003-0655-6838 \\ admilson.irio@unesp.br
}

Referencing this:

SOUSA, J. A. P.; SOUZA, J. C.; CALI, B. P.; MEDEIROS, G. A.; RIBEIRO, A. Í.. Atividade biológica percebida e indicadores edáficos em uma área de fruticultura periurbana. Revista Ibero Americana de Ciências Ambientais, v.12, n.3, p.1-12, 2021. DOI:

http://doi.org/10.6008/CBPC2179-6858.2021.003.0001 


\section{INTRODUÇÃO}

A falta de planejamento urbano é considerada um dos principais problemas da sociedade moderna (AQUINO et al., 2007). Em vista disso, a expansão das atividades industriais e do sítio urbano sobre as áreas rurais, tornou a realidade periférica das cidades mais complexa, gerando problemas sociais e ambientais diversos. Nessas áreas tem se expandido a agricultura periurbana, definida como aquela que ocorre nas fronteiras das cidades (SOUZA et al., 2017), voltadas principalmente à promoção do desenvolvimento sustentável dos espaços urbanizados (SILVA et al., 2018).

A agricultura periurbana, por sua proximidade com as áreas rurais, tem influenciado positivamente a dinâmica agrícola tradicional, combinando o trabalho rural com o não-rural, como a adoção de medidas conservacionistas e de produção orgânica. Logo, esse tipo de atividade se tornou de fundamental importância para proporcionar maior equilíbrio social, conservação ambiental e segurança alimentar (MACHADO et al., 2002). Dentre as principais funções ecossistemas desta atividade, podemos destacar as práticas de conservação dos solos.

A importância da agricultura periurbana para o solo se embasa principalmente no fato de utilizar métodos de cultivos que visam reduzir a degradação deste recurso natural. Segundo Machado (2019), a menor interferência no solo e a utilização de práticas voltadas a sua conservação contribuem para a redução da suscetibilidade a erosão e, devido a adoção de rotatividade de culturas e de coberturas, há a possibilidade de enriquecimento do solo por meio de nutrientes e matéria orgânica.

Neste contexto, ressalta-se a necessidade de repensar as práticas de cultivo e as formas de manejo do solo, na perspectiva da produção de serviços ecossistêmicos, definidos como o conjunto de benefícios propiciados pelos ambientes naturais (DAILY et al., 1997). Os serviços ecossistêmicos proporcionados pelo solo estão relacionados à sua capacidade de promover a produtividade biológica, a diversidade microbiana e da micro e macrofauna, a qualidade e o suprimento de água, atenuação da poluição e degradação, o equilíbrio entre os condicionantes químico, físico e biológico, assim como sua capacidade de suportar o bemestar humano (PULLEMAN et al., 2012; BRUSSAARD, 2012; ARAÚJO et al., 2007; BARRIOS, 2007; CORDEIRO et al., 2004).

A alteração nos ecossistemas e as práticas agrícolas que envolvem o uso intensivo de insumos pode suprimir a capacidade das terras agrícolas de promover esses serviços de forma satisfatória (SANDHUA et al., 2008). Nesse contexto, se insere o termo qualidade do solo, o qual está relacionado principalmente a produtividade biológica bem como com a qualidade ambiental, podendo ser avaliada por meio de indicadores edáficos. O critério para o uso de um parâmetro como indicador do solo é a sua capacidade de interferir nos processos ecológicos, integrar as propriedades físicas, químicas e biológicas, além de ser facilmente utilizável por especialistas, técnicos e agricultores (ARAÚJO et al., 2007).

Frente a essas questões, o presente estudo teve por objetivo caracterizar as condições físicas e biológicas dos solos em uma área de fruticultura periurbana, buscando compreender as relações entre as variáveis e contribuir para o entendimento das formas de manejo e uso da terra e os impactos ambientais 
relacionados.

\section{MATERIAIS E MÉTODOS}

\section{Área de estudo}

O estudo foi realizado em novembro de 2016 em uma propriedade de aproximadamente 9,67 ha, localizada na cidade de Jundiaí (Figura 1). O local se situa entre as regiões metropolitanas de São Paulo e Campinas, em uma distância aproximada de $40 \mathrm{~km}$ de ambas. A área possui altitude em torno de $762 \mathrm{~m} \mathrm{e}$ posicionamento geográfico entre as coordenadas $23^{\circ} 12^{\prime} / 23^{\circ} 21^{\prime}$ latitude Sul e $46^{\circ} 30^{\prime} / 47^{\circ} 05^{\prime}$ longitude Oeste.

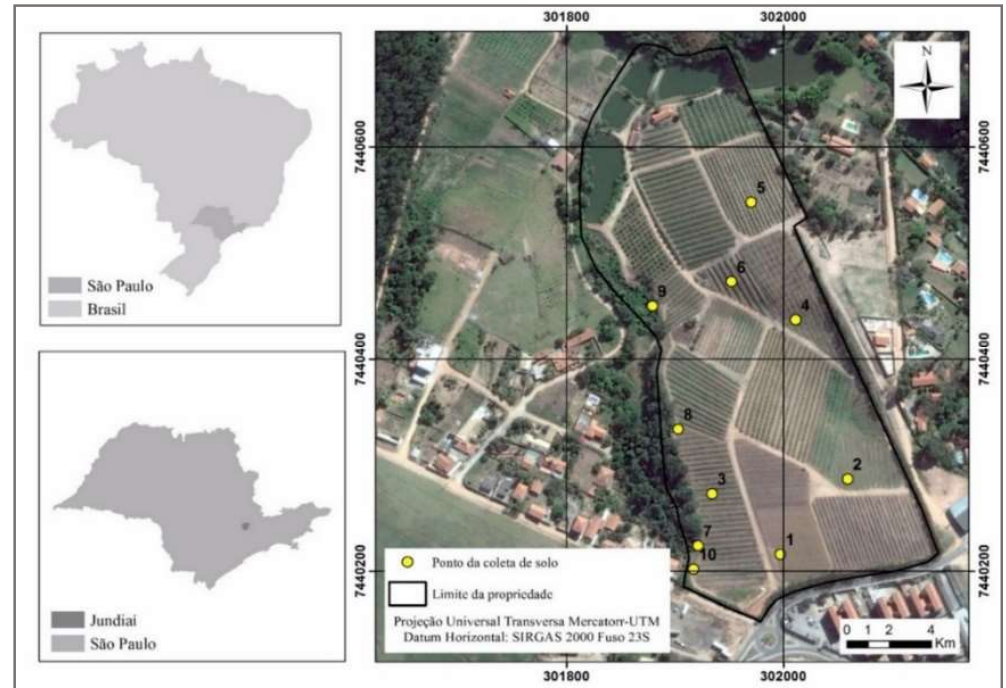

Figura 1: Localização área de estudo e pontos de amostragem, situada no município de Jundiaí, estado de São Paulo, Brasil.

O município apresenta o relevo predominantemente ondulado, e contêm áreas preservadas de grande interesse ambiental. A classificação climática da região é do tipo Cwa, compreendido como Clima subtropical de inverno seco e verão úmido e quente (DUBREUIL et al., 2017), com pluviosidade média mensal de 218mm (IAC, 2013). O município se localiza no domínio fitogeográfico da mata Atlântica, com ocorrência predominante da Floresta Ombrófila Densa (IBGE, 2019). Os tipos de solos que ocorrem no município são o Cambissolo, Gleissolo, Latossolo, Argissolo e Neossolo (ROSSI, 2017).

As condições meteorológicas no dia da coleta e nos dez dias que a antecederam, apresentaram uma variação na temperatura de $15^{\circ} \mathrm{C}$ a $23^{\circ} \mathrm{C}$, umidade relativa média do ar entre $58 \%$ e $93 \%$, e os totais de chuva diários mais significativos foram nos dias 14/11/2016 (22,61mm) e 17/11/2016 (16,76mm). Nos três dias que precederam a coleta de dados observou-se índices diários de precipitação inferiores a $2 \mathrm{~mm}$ (20 de novembro) ou ausência de chuvas (21, 22 e 23 de novembro) (CIIAGRO, 2016).

\section{Identificação de elementos de destaque na paisagem}

A paisagem pode ser definida como um ambiente percebido pelas pessoas, sendo o reflexo de uma série de pressões antrópicas sobre o meio ambiente, como assentamentos humanos, uso agrícola, estruturas de comunicação e transporte, áreas de recreação e fragmentação de habitat (ANTROP, 2000). Para 
Christofoletti (1999) a paisagem é uma categoria de investigação espacial, onde é possível compreender o território como um sistema ambiental, físico e socioeconômico integrado, com estruturação, funcionamento e dinâmica. A análise da paisagem é uma abordagem metodológica que vem sendo utilizada em estudos relacionados a gestão dos recursos naturais, em diferentes escalas e procedimentos metodológicos, como Carli et al. (2018), Medeiros et al. (2016), Marques (2016), Fengler et al. (2015).

A definição dos pontos de amostragem se baseou no mapa de fluxos gerado a partir do modelo digital do terreno (Figura 2), definindo ambientes de acúmulo e de perda de água, além da cobertura do solo. Tais pontos, em um total de dez, estão assinalados na Figura 1.

Definidos os locais de amostragem, procedeu-se à identificação dos elementos de destaque na paisagem em cada ponto amostrado, seguindo abordagem metodológica descrita por Medeiros et al. (2016).

\section{Análise in loco da atividade biológica}

O levantamento da diversidade biológica na área de estudo ocorreu no dia 23 de novembro de 2016. A diversidade biológica foi amostrada utilizando um quadrante de $0,5 \mathrm{~m}^{2}$ composto por um grid com espaçamento de $5 \mathrm{~cm}$ por $5 \mathrm{~cm}$, totalizando 100 células (RIBEIRO et al., 2012).

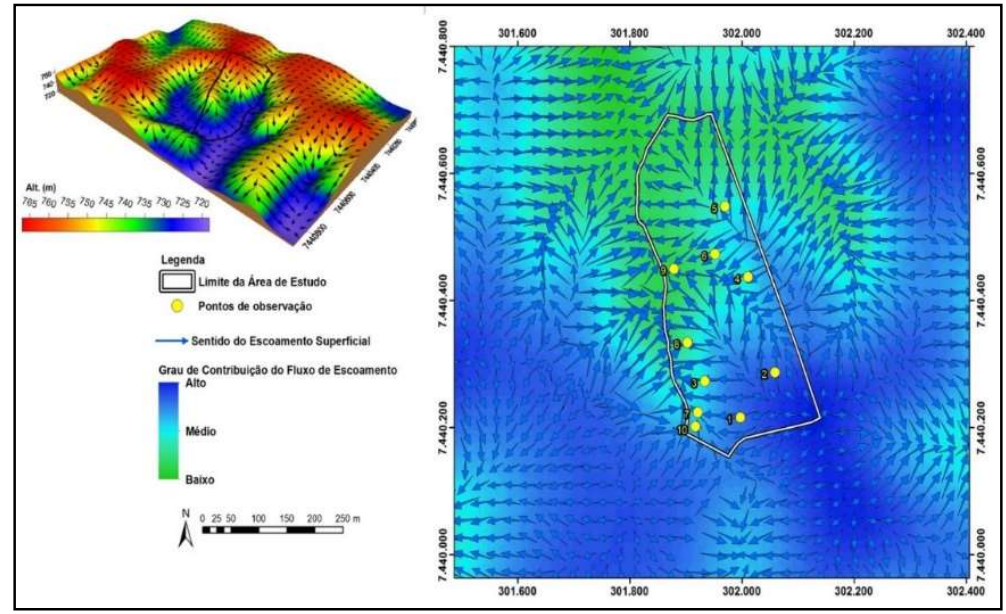

Figura 2: Representação do escoamento superficial e altimetria da área de produção agrícola periurbana, em Jundiaí, estado de São Paulo.

Nos locais de amostragem foram avaliados visualmente e contabilizados, em cada célula do grid, os seguintes parâmetros: cobertura vegetal (CV), cobertura morta (CM), fungos visíveis (FV), bioturbação (B) e raízes (R). A totalização da contagem em cada ponto foi dividida pelo número de células do grid (100), obtendo-se um percentual (\%) de cada parâmetro no ponto amostrado.

Em todos os pontos realizaram-se registros fotográficos, os quais foram processados no software ArcGis 10.3 (ESRI, 2014), para obter uma classificação automática. Assim, com o uso do comando Iso Cluster Unsupervised Classification foi realizada uma quantificação da vegetação verde, vegetação seca e solo exposto.

\section{Parâmetros edáficos}

Em cada ponto de amostragem foi realizada uma caracterização da declividade, resistência do solo à 
penetração (RSP) e coleta de solo na superfície (até $10 \mathrm{~cm}$ de profundidade), por meio de anéis volumétricos. As análises físicas foram realizadas no Laboratórios de Águas e Solos (LAS), da Universidade Estadual Paulista (Unesp), Campus Sorocaba. Todos os parâmetros físicos avaliados, além da matéria orgânica, foram relativos a essa profundidade amostrada.

A declividade em cada ponto foi estimada com o auxílio de uma mira topográfica e teodolito. Já a RSP foi levantada por meio de um penetrômetro de impacto de Stolf (STOLF et al., 2014), considerando a profundidade de 0 - $40 \mathrm{~cm}$ (Equação 1).

$$
\mathrm{RSP}=(0,56+0,689) *(10 * \mathrm{ni})
$$

Em que: RSP é a resistência do solo à penetração (MPa) e ni é o número de impactos registrados por meio do penetrômetro de impacto (número de impactos por decímetro de solo).

Foram levantadas as seguintes variáveis do solo: umidade (U); peso específico aparente do solo seco $\left(\gamma_{s}\right)$; índice de vazios $(\varepsilon)$; porosidade $(\vartheta)$; diâmetro médio geométrico $(D M G)$. As metodologias e equações utilizadas para a determinação desses parâmetros são apresentadas na Tabela 1 (EMBRAPA, 1997; MAZURAK, 1950).

Tabela 1: Levantamento das varáveis físicas do solo.

\begin{tabular}{l|c}
\hline Variável física do solo & Equação \\
\hline Teor de umidade (\%) & $\mathrm{U}=\left(\frac{\mathrm{Pa}-\mathrm{Ps}}{P s}\right) * 100$ \\
\hline Peso específico aparente do solo seco $\left(\mathrm{g} / \mathrm{cm}^{3}\right)$ & $\gamma \mathrm{s}=\frac{\mathrm{Ps}}{\mathrm{Vt}}$ \\
\hline Índice de vazios (adimensional) & $\varepsilon=\frac{\mathrm{Vv}}{\mathrm{Vs}}$ \\
\hline Porosidade (\%) & $\theta=\left(\frac{\mathrm{Vv}}{\mathrm{Vt}}\right) * 100$ \\
\hline Diâmetro médio geométrico $(\mathrm{mm})$ & $\mathrm{DMG}=10^{\left[\frac{\sum(\mathrm{n} \cdot \operatorname{logd})}{\sum \mathrm{n}}\right]}$ \\
\hline
\end{tabular}

Legenda: $P_{a}$ - peso da amostra em estado natural; $P_{s}$ - peso da amostra seca; $P_{t}$ - peso total da amostra; $V_{t}$ - volume total; $V_{v}$ - volume de vazios; $V_{s}$ - volume da parte sólida do solo; $n$ - porcentagem de agregados retida em cada peneira; $d$ diâmetro médio dos agregados.

O teor de matéria orgânica foi determinado por calcinação em mufla, utilizando 10 gramas das amostras de solo submetidas a temperatura de $550{ }^{\circ} \mathrm{C}$, por 4 horas. A diferença entre o peso inicial e o final correspondeu à quantidade de matéria orgânica (EMBRAPA, 1997). Com os dados obtidos aplicou-se a seguinte equação para o teor de matéria orgânica (MO):

$$
M O=\left(\frac{P s-P m}{P s}\right) * 100
$$

Em que: MO é o teor de matéria orgânica do solo (\%); $P_{s}$ o peso inicial da amostra (g); $P_{m}$ o peso da amostra pós calcinação em mufla (g).

\section{Análise estatística}

Para a padronização dos dados foi utilizada a metodologia proposta por Milligan et al. (1988). As análises estatísticas, gráficos e as tabelas foram desenvolvidos com uso planilha do Excel versão 1909. 


\section{RESULTADOS}

\section{Análise dos elementos de destaque na paisagem}

$\mathrm{Na}$ identificação dos elementos de destaque da paisagem, relativa a cada ponto amostral, foram constatadas as características apresentadas na Tabela 2, correlatas aos tipos de cultivo e manejo do solo, ocorrência de erosão, grau de compactação dos solos e a diversidade biológica. Todas as espécies de frutas cultivadas são permanentes, e em três talhões foram identificados o tipo de cultivo por consórcio. Dos dez pontos avaliados, seis apresentaram superfície adensada (pontos 2, 4, 5, 6, 7 e 10). No ponto 1 foi observada a maior diversidade biológica percebida, dentre os pontos avaliados. Processos erosivos foram identificados em cinco pontos amostrais, sendo uma ocorrência de erosão do tipo ravina e as demais do tipo laminar.

Tabela 2: Descrição dos elementos de destaque na paisagem, incluindo o tipo de manejo do solo e condições ambientais dos pontos avaliados, em área de produção agrícola periurbana no município de Jundiaí, estado de São Paulo, Brasil.

\begin{tabular}{l|l}
\hline Pontos & Elementos de destaque da paisagem \\
\hline 1 & Cultivo de uva. Plantio feito no sentido do declive. Boa diversidade biológica percebida. Não apresentou sinais de erosão. \\
\hline 2 & Cultivo de seriguela e caqui. Solo superficialmente adensado. Evidência de erosão laminar. \\
\hline 3 & $\begin{array}{l}\text { Cultivo de goiaba. Evidências de erosão laminar. Baixa diversidade biológica percebida. Abundância de raízes na } \\
\text { superfície. }\end{array}$ \\
\hline 4 & $\begin{array}{l}\text { Cultivo de caqui. Baixa diversidade da macrofauna. Solo superficialmente adensado. Uso de herbicida. Não apresentou } \\
\text { sinais de erosão. }\end{array}$ \\
\hline 5 & Cultivo de goiaba. Pouca diversidade da macrofauna. Solo superficialmente adensado. Não apresentou sinais de erosão. \\
\hline 7 & $\begin{array}{l}\text { Cultivo de caqui e goiaba. Pouca diversidade da macrofauna. Solo superficialmente adensado. Presença de calcário e } \\
\text { palhada. Não apresentou sinais de erosão. }\end{array}$ \\
\hline 8 & $\begin{array}{l}\text { Célula de drenagem (área de concentração de fluxo de água). Solo sem diversidade biológica percebida. Solo } \\
\text { superficialmente adensado. Ocorrência de erosão laminar. }\end{array}$ \\
\hline 9 & Cultivo de Goiaba. Solo com serapilheira. Matéria orgânica evidente. Ocorrência de erosão laminar. \\
\hline 10 & Cultivo de caqui e lichia. Ocorrência de erosão laminar. \\
\hline
\end{tabular}

\section{Indicadores edáficos}

A Figura 3 apresenta os resultados dos parâmetros de porosidade, índice de vazios, diâmetro médio geométrico (DMG), peso especifico aparente do solo seco (PEASS) e matéria orgânica (MO). Na Figura 3A pode-se observar que a porosidade variou de $23,7 \%$ a $63,8 \%$, sendo o máximo observado no ponto 3 (cultivo de goiaba) e o mínimo no ponto 7 (área sem cultivo).

O Índice de vazios (Figura 3B) variou de 0,31\% a 1,76\%, seguindo a mesma tendência da porosidade, ou seja, o máximo no ponto 3 e o mínimo no ponto 7. Na Figura 3 C observou-se que os valores do DMG variaram de $0,75 \mathrm{~mm}$ (ponto 9) a $0,92 \mathrm{~mm}$ (pontos 2 e 3), sendo que, no ponto 9 desenvolviam-se os cultivos de caqui e lichia e no ponto 2 seriguela e caqui.

Na Figura 3D, observa-se que o ponto 7 foi aquele que registrou o maior valor de PEASS $(2,02 \%)$, enquanto o ponto 3 atingiu o menor (0,96\%). Os valores de matéria orgânica, apresentados na Figura 3E, indicaram o ponto 9 com o menor valor $(4,39 \%)$ e o ponto 3 com o maior valor $(25,65 \%)$.

Os pontos 1, 2, 3, 4, 5, 6 e 8 estão em área de dispersão do escoamento superficial, já os pontos 7, 9 e 10 estão em área de convergência de fluxo. Estes resultados estão de acordo com as observações de campo, e indicam uma relação do direcionamento do fluxo com as características apresentadas na Figura 3. O escoamento superficial contribuiu para os processos erosivos e a remoção da matéria orgânica e nutrientes, 
como observado no ponto 7. Nesse ponto foram registrados baixos teores de matéria orgânica, os menores índices de vazios e porosidade, além de alto valor para o PEASS.

A Figura 4 apresenta os resultados da resistência do solo à penetração (RSP). A RSP é um parâmetro relacionado a densidade, compacidade e macroporosidade do solo, sendo um importante indicador da qualidade deste.

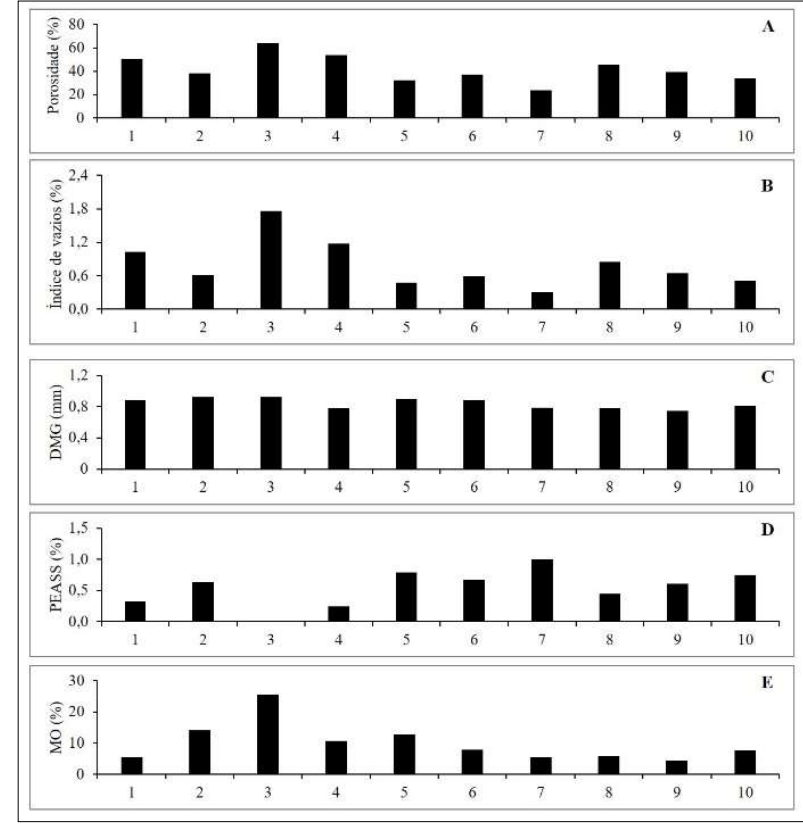

Figura 3: Gráfico com a representação dos pontos e os parâmetros analisados.

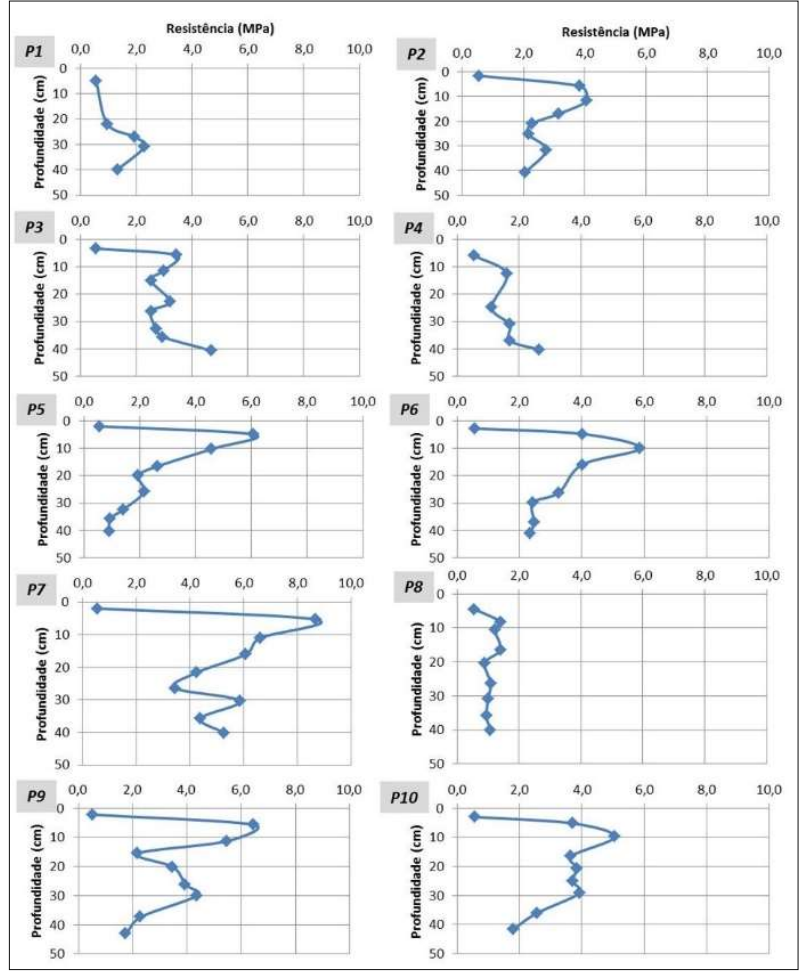

Figura 4: Resistência do solo à penetração (RSP) em área de produção agrícola periurbana no município de Jundiaí, estado de São Paulo, Brasil.

Elevada resistência mecânica do solo à penetração restringe o desenvolvimento radicular das plantas e reduz a biodiversidade da fauna endopedônica (CAMPOS et al., 2013; SOUZA et al., 2003). Nos pontos 2, 5, 6, 7, 9 e 10 foram identificados valores máximos de RSP entre as profundidades de 5 e $10 \mathrm{~cm}$. A partir dos 10 $\mathrm{cm}$ percebeu-se uma redução significativa na RSP desses pontos. Estas condições podem estar relacionadas ao tipo de cultivo, pois a fruticultura, por ser uma cultura perene, não demanda um revolvimento do solo por aração de forma tão frequente quanto na cultura anual. Entre as profundidades de 20 e $30 \mathrm{~cm}$ ocorreu outro aumento na resistência, mas desta vez menos acentuado.

\section{Análise da atividade biológica diversificada}

Os resultados da atividade biológica diversificada são apresentados na Figura 5. Foram levantados o percentual de bioturbação, insetos e fungos percebidos visualmente, após a retirada da cobertura vegetal da superfície. A bioturbação do solo é o resultado do processo de mistura e deslocamento do material orgânico e mineral da superfície e subsolo, promovido pela fauna endopedônica (SILVA et al., 2007).

O ponto7, localizado na área de solo exposto, registrou ausência de fungos visíveis e insetos. Nesse ponto foi registrado o mais baixo valor de matéria orgânica e porosidade (Figura 3), sugerindo as condições 
mais desfavoráveis ao desenvolvimento e manuntenção da diversidade biológica.

Na Figura 6 pode-se visualizar um mosaico da cobertura vegetal dos locais amostrados. Os pontos 1 , 2, 5 e 9 são aqueles que apresentaram a maior porcentagem de cobertura verde. Nos pontos 7 e 10 não haviam quaisquer tipos de cobertura, por serem locais de acúmulo de água e sedimentos. Nos pontos 3 e 4 observou-se um ressecamento evidente da vegetação devido a aplicação de herbicida, antes da data do levantamento.

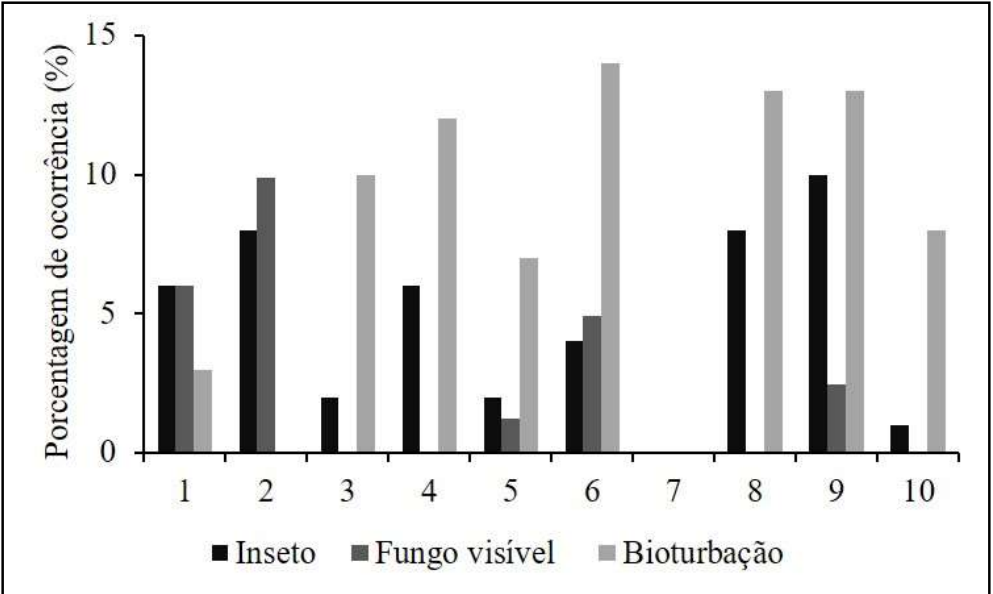

Figura 5: Atividade biológica diversifica dos pontos amostrais (\%)

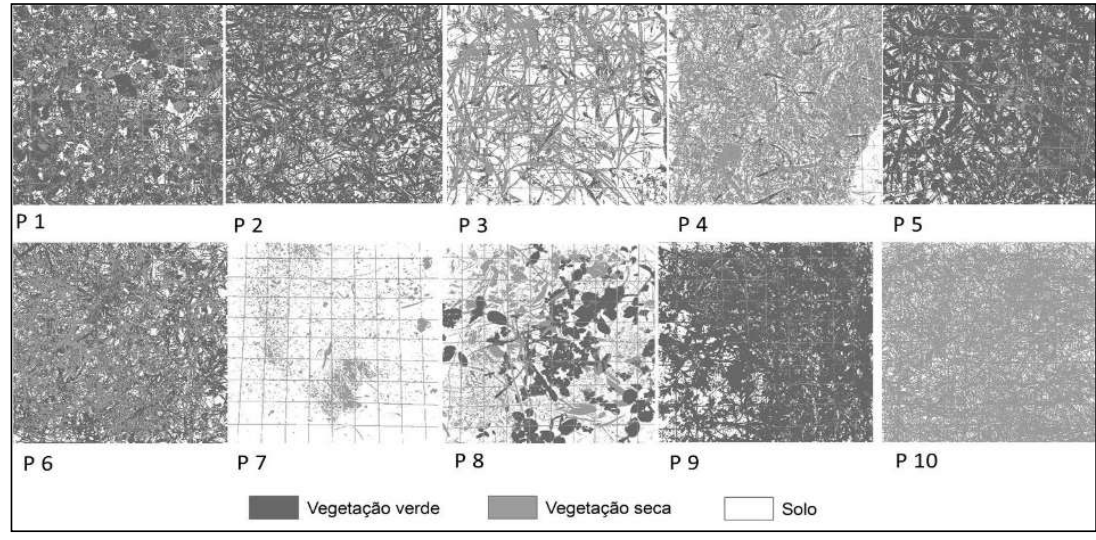

Figura 6: Mosaico das imagens classificadas.

O percentual das classes de cobertura do solo apresentados na Tabela 3 foram calculados a partir da classificação das imagens (Figura 6). Os resultados indicaram que os pontos 1, 2, 5, 6 e 9 atingiram índices de cobertura verde acima de $50 \%$.

Tabela 3: Percentual das classes de cobertura do solo das imagens classificadas.

\begin{tabular}{l|l|l|l}
\hline \multirow{2}{*}{ Ponto } & Classes em (\%) & Vegetação seca & Solo \\
\cline { 2 - 4 } & Vegetação verde & 27,48 & 14,26 \\
\hline 1 & 58,26 & 10,83 & 21,07 \\
\hline 2 & 68,10 & 32,94 & 47,00 \\
\hline 3 & 20,06 & 61,68 & 28,96 \\
\hline 4 & 9,36 & 9,44 & 15,00 \\
\hline 5 & 75,56 & 30,00 & 19,44 \\
\hline 6 & 50,56 & 8,94 & 91,06 \\
\hline 8 & 0,00 & 29,77 & 46,82 \\
\hline 10 & 23,41 & 5,20 & 14,66 \\
\hline
\end{tabular}




\section{DISCUSSÃO}

A superfície adensada (Tabela 2) pode estar relacionado ao trânsito de máquinas agrícolas. Já a erosão do tipo ravina é resultado da concentração do escoamento superficial em trechos côncavos do relevo ou em caminhos preferênciais, produzidos pelas atividades de cultivo. A erosão laminar é resultado do processo de salpicamento, associado ao escoamento difuso das águas das chuvas, que promove a remoção progressiva dos horizontes superficiais do solo, especialmente a camada humífera, o que potencializou os casos de assoreamento dos cursos d'água e reservatórios da propriedade (BERTONI et al., 2014).

A partir dos resultados apresentados na Figura 3, pode-se inferir que há uma relação entre a matéria orgânica, a porosidade e o índices de vazios, pois se observou que os pontos que apresentaram os menores valores desses parâmetros foram os mesmos. Verificou-se uma relação inversa entre a matéria orgânica e o PEASS, ou seja, quanto maior o teor de matéria orgânica, menor o valor de PEASS e vice-versa.

Para a adoção de um sistema de manejo conservacionista eficiente é indispensável, dentre outras condições, o conhecimento do processo erosivo em seus aspectos quantitativos e qualitativos, bem como suas relações com outros fatores do meio (BOARETT et al., 1998). Nesse sentido, o conhecimento do regime de chuvas e da suscetibilidade dos solos a erosão tornam-se importantes para o planejamento conservacionista, contribuindo para a sustentabilidade dos solos (SILVA et al., 2009).

A avaliação da qualidade do solo, associada com outros fatores do meio, é uma importante informação para a definição de diretrizes de uma gestão sustentável da produção agrícola. Nesse viés, parâmetros do solo associados a agregação, como o diâmetro médio geométrico (DMG) e matéria orgânica, ao armazenamento de água (índice de vazios e porosidade), e a promoção de condições favoráveis ao desenvolvimento radicular, como o peso específico e a resistência do solo à penetração (RSP) têm sido utilizados para inferências sobre a qualidade do solo (RIBEIRO et al., 2012; LONGO et al., 2012; MEDEIROS et al., 2012; MEDEIROS et al., 2009).

Apesar do ponto 9 apresentar cobertura vegetal, os seus indicadores edáficos foram similares ao ponto 7, ressaltando o efeito do fluxo de água e, como consequência, a erosão. Segundo Dechen et al. (2015), a erosão hídrica é considerada um dos principais fatores responsáveis pela desagregação do solo.

A matéria orgânica e a porosidade exercem influência direta na estrutura do solo, por interferirem na estabilidade dos agregados, na estrutura e na permeabilidade (PALM et al., 2007). A alta porosidade associada a matéria orgânica pode promover uma maior infiltração de água e prevenir o escoamento superficial, reduzindo a vulnerabilidade do solo a erosão hídrica (GUERRA, 2001).

Os pontos 5, 6, 7 e 9 (Figura 4) apresentaram os maiores valores em RSP até a profundidade de 10 $\mathrm{cm}$, variando de 5,9 a 8,7 MPa, considerados elevados tendo em vista que RSP superiores a 2,0 MPa já apresentam limitações para desenvolvimento de raízes (SOUZA et al., 2003; TAVARES FILHO et al., 2001; BEUTLER et al., 2001; IMHOFF et al., 2000).

Considerando a média (5,0 MPa) e o valor máximo observado (8,7 MPa), o perfil do solo no ponto 7 foi o que apresentou a maior RSP. Este ponto é uma área de confluência de fluxo de água superficial associado 
ao trânsito de maquinários agrícolas, justificando assim os altos valores de RSP observados. 0 ponto 8 foi aquele que apresentou uma maior uniformidade de valores de RSP ao longo de todo o perfil, média de 1,1 $\mathrm{MPa}$, amplitude de $0,6 \mathrm{MPa}$ a $1,4 \mathrm{MPa}$ e coeficiente de variação de $27 \%$. 0 ponto que apresentou os valores mais heterogêneos foi o 5, com média de 2,4 MPa, amplitude de 1,0 MPa a 6,2 MPa e coeficiente de variação de $75 \%$.

No sistema de manejo dos pontos 1, 2, 5, 6 e 9 foi identificado o uso de palhada, oriunda dos resíduos de poda da área urbana de Jundiaí. A utilização dessa palhada proporcionou a manutenção da umidade do solo. $\mathrm{O}$ ponto 2 foi o que apresentou a maior quantidade de insetos e fungos visíveis, o que pode estar associado à maior quantidade de cobertura vegetal verde (68,10\%). Ribeiro et al. (2012) afirmam que existe uma proporcionalidade entre a cobertura vegetal e a atividade biológica diversificada, e que esse fenômeno está relacionado com o teor de matéria orgânica.

No Ponto 6 verificou-se a maior ocorrência de bioturbação (14 \%), seguido dos pontos 8 e 9 com 13\% cada. No entanto, o ponto 7 não foram observados insetos, fungos visíveis ou bioturbação, indicando condições desfavoráveis para o desenvovimento e sobrevivência da fauna edáfica.

Os pontos 4 e 10 apresentaram os maiores percentuais de cobertura seca (Tabela 3), superando 60\%. No ponto 4 ficou evidenciado o uso de herbicida para conter o crescimento da vegetação, provocando um ressecamento visível. No ponto 10 , além de ser uma área de manobra de máquinas agrícolas, trata-se de um ponto que concentra o fluxo de escoamento superficial. Por esses motivos, apresentou ocorrência de processos erosivos e uma baixa diversidade biológica.

O ponto 7 foi o que apresentou o maior percentual de solo exposto, superior a $90 \%$, contribuindo para as condições desfavoráveis de suporte a fauna. No ponto 3 também se observou o uso de herbicida para conter o crescimento da vegetação e, em função disso, houve um considerável percentual de solo exposto. O ponto 8 valor próximo ao ponto 3, no entanto a vegetação mostrava-se sadia e com vigor.

\section{CONCLUSÕES}

A agricultura periurbana é uma modalidade de cultivo de extrema importância para atender a demanda por alimentos, para a geração de emprego e renda para os habitantes da periferia das cidades e pela função que exerce na produção de serviços ecossistêmicos, quando se utiliza práticas de cultivo conservacionistas e de produção orgânica.

A avaliação da área de estudo, integrando as descrições e levantamento de campo com as análises laboratoriais, sinalizou que a ocorrência de processos erosivos é agravada pelas condições de plantio alinhada no sentido do declive.

As práticas conservacionistas, como a manutenção da palhada na superfície, além de preservar a umidade, promoveram a proteção do solo contra os processos erosivos. Essa proteção também potencializou o desenvolvimento da diversidade biológica percebida, a bioturbação e a produção de matéria orgânica.

A presença da macrofauna se mostrou um bom indicador de qualidade dos solos, relacionando-se diretamente com os maiores teores de matéria orgânica e porosidade, e inversamente com a resistência do 
solo a penetração.

\section{REFERÊNCIAS}

ANTROP, A.. Background concepts from integrated landscape analysis. Agriculture, Ecosystems and Environment, v.77, p.17-28, 2000. DOI: https://doi.org/10.1016/S0167-8809(99)00089-4

AQUINO, A. M.; ASSIS, R. L.. Agricultura Orgânica em Áreas Urbanas e Periurbanas com Base na Agroecologia. Ambiente \& Sociedade, Campinas, v.10, n.1, p.137-150, 2007.

ARAÚJO, A. S. F.; MONTEIRO, R. T. R.. Indicadores biológicos de qualidade do solo. Biosci. J., Uberlândia, v.23, n.3, p.6675, 2007.

BARRIOS, E.. Soil biota, ecosystem services and land productivity. Ecological Economics, v.64, p.269-285, 2007. DOI: https://doi.org/10.1016/j.ecolecon.2007.03.004

BERTONI, J.; LOMBARDI NETO, F.. Conservação do solo. 9 ed. São Paulo: Ícone, 2014.

BEUTLER, A. N.; SILVA, M. L. N.; CURI, N.; FERREIRA, M. M.; CRUZ, J. C.; PEREIRA FILHO, I. A.. Resistência à penetração e permeabilidade de Latossolo Vermelho distrófico típico sob sistemas de manejo na região dos cerrados. Revista Brasileira de Ciência do Solo, Viçosa, v.25, n.1, p.167-177, 2001. DOI: http://dx.doi.org/10.1590/S0100$\underline{06832001000100018}$

BOARETT, W. A.; SOUZA, C. M.; WRUCK, F. J.. Índice de erosividade das chuvas para Viçosa/MG. Revista Ceres, v.45, n.258, p.193-201, 1998.

BRUSSAARD, L.. Ecosystem Services Provided by the Soil Biota. In: WALL, D. H.; BARDGETT, R. D.; BEHAN-PELLETIER, V.; HERRICK, J. E.; JONES, H.; RITZ, K.; SIX, J.; STRONG, D. R.; VAN DER PUTTEN, W. H.. Soil ecology and ecosystem services. Oxford: Oxford University Press, 2012. p.1-17. DOI: http://doi.org/10.1093/acprof:oso/9780199575923.003.000 $\underline{5}$

CAMPOS, M. C. C.; AQUINO, R. E.; OLIVEIRA, I. A.; BERGAMIM, A. C.. Variabilidade espacial da resistência mecânica do solo à penetração e umidade do solo em área cultivada com cana-de-açúcar na região de Humaitá, Amazonas, Brasil. Revista Brasileira de Ciências Agrárias, Recife, v.8, p.305-310, 2013. DOI:

http://doi.org/10.5039/agraria.v8i2a2091

CARLI, B. P.; SOUZA, J. S.; SOUSA, J . A. P.; SHOEGIMA, T. F.; BARREIRO, M. D. P. R.; DUTRA, A. C.; MEDEIROS, G. A.; RIBEIRO, A. I .; BRESSANE, A.. Relationship between land use and water quality in a subtropical river basin. Fronteiras: Journal of Social, Technological and Environmental Science, v.7, n.3, p.245-261, 2018. DOI:

https://doi.org/10.21664/2238-8869.2018v7i3.p245-261

CIIAGRO. Centro Integrado de Informações

Agrometeorológicas. Precipitação. CIIAGRO, 2016.

CORDEIRO, F. C.; DIAS, F. C.; MERLIM, A. O.; CORREIA, M. E. F.; AQUINO, A. M.; BROWN, G.. Diversidade da macrofauna invertebrada do solo como indicadora da qualidade do solo em sistema de manejo orgânico de produção. Rev. Univ. Rural, Sér. Ci. Vida, Seropédica, v.24, n.2, p.29-34, 2004.

CHRISTOFOLETTI, A.. Modelagem de Sistemas Ambientais. São Paulo: Blucher, 1999.

DAILY, G. C.; ALEXANDER, S.; EHRLICH, P.R.; GOULDER, L.; LUBCHENCO, J.; MATSON, P. A.; MOONEY, H. A.; POSTEL, S.; SCHNEIDER, S. H.; TILMAN, D.; WOODWELL, G. M.

Ecosystem services: benefits supplied to human societies by natural ecosystems. Issues in Ecology, n.2, p.1-16, 1997.

DECHEN, S. C. F.; TELLES, T. S.; GUIMARÃES, M. F.; MARIA, I. C.. Perdas e custos associados à erosão hídrica em função de taxas de cobertura do solo. Bragantia, Campinas, v.74, n.2, p.224-233, 2015. DOI: http://dx.doi.org/10.1590/16784499.0363

DUBREUIL, V.; FANTE, K. P.; PLANCHON, O.; SANT'ANNA NETO, J. L.. Les types de climatsannuels au Brésil: une application de la classification de Köppen de 1961 a 2015. EchoGéo, v.41, p.01-27, 2017. DOI: https://doi.org/10.4000/echogeo.15017

EMBRAPA. Empresa Brasileira de Pesquisa Agropecuária. Manual de métodos de análise de solo. 2 ed. Rio de Janeiro: EMBRAPA, 1997.

ESRI. Environmental Systems Research Institute. ArcGIS 10.3. ESRI, 2014.

FENGLER, F. H.; MORAES, J. F. L.; RIBEIRO, A. I.; PECHE FILHO, A.; STORINO, M.; MEDEIROS, G. A.. Qualidade ambiental dos fragmentos florestais na Bacia Hidrográfica do Rio JundiaíMirim entre 1972 e 2013. Revista Brasileira de Engenharia Agrícola e Ambiental, v.19, p.402-408, 2015. DOI: https://doi.org/10.1590/1807-1929/agriambi.v19n4p402$\underline{408}$

GUERRA, A. T.. Processos Erosivos nas Encostas. In: GUERRA, A. J. T.; CUNHA, S. B. C.. Geomorfologia uma Atualização de Bases e Conceitos. 4 ed. Rio de Janeiro: Bertrand Brasil, 2001.

IBGE. Instituto Brasileiro de Geografia e Estatística. Banco de Dados de Informações Ambientais. IBGE, 2019.

IMHOFF, S.; SILVA, A. P.; TORMENA, C. A.. Aplicações da curva de resistência no controle da qualidade física de um solo sob pastagem. Pesq. Agropec. Bras., Brasília, v.35 n.7, p.1493-1500, 2000. DOI: https://doi.org/10.1590/S0100204X2000000700025

IAC. Instituto Agronômico de Campinas. Polo Turístico do Circuito das Frutas do Estado de São Paulo: Fisiografia e Clima. Boletim Técnico IAC. Campinas: Instituto Agronômico de Campinas, 2013.

LONGO, R. M.; REIS, M. S.; YAMAGUCHI, C. S.; DEMAMBORO, A. C.; BETTINE, S. C.; RIBEIRO, A. Í.; MEDEIROS, G. A.. Indicators of soil degradation in urban forests: physical and chemical parameters. WIT Transactions 
on Ecology and the Environment, v.162, p.497-503, 2012. DOI: http://dx.doi.org/10.2495/EID120431

MACHADO, G. B.. Agricultura produtivista à agricultura multifuncional no sistema agrário do cacau. Braz. J. of Develop., Curitiba, v.5, n.9, p.13868-13890, 2019. DOI: https://doi.org/10.34117/bjdv5n9-017

MACHADO, A. T.; MACHADO, C. T. T.. Agricultura Urbana. EMBRAPA Documentos 48. Ministério da Agricultura, Pecuária e Abastecimento, 2002.

MARQUES, B. V.. Avaliação dos ambientes de proteção da bacia hidrográfica do rio Jundiaí-Mirim/SP. Dissertação (Mestrado em Ciências Ambientais) - Universidade de Estadual Paulista, Sorocaba, 2016.

MAZURAK, A. P.. Effect of gaseous phase on waterstablesynthetic aggregates. Soil Sci., v.69, p.135-148, 1950.

MEDEIROS, G. A.; DANIEL, L. A.; LUCARELLI, J. R. F.; REIS, F. A. G. V.. Influência do sistema de preparo e manejo de um Latossolo vermelho nas suas propriedades físico-hídricas. Geociências, v.28, p.453-465, 2009.

MEDEIROS, G. A.; DANIEL, L. A.; LUCARELLI, J. R. F.; ESPÍNDOLA, C. R.; RIBEIRO, A. Í.; REIS, F. A. G. V.; LONGO, R. M.. Restoration of a degraded area using soil tillage systems in Campinas, São Paulo, Brazil. WIT Transactions on Ecology and the Environment, v.162, p.243-252, 2012. DOI: http://dx.doi.org/10.2495/EID120221

MEDEIROS, G. A.; MARQUES, B. V.; FENGLER, F. H.; MACHADO, F. H.; MORAES, J. F. L.; PECHE FILHO, A.; LONGO, R. M.; RIBEIRO, A. I.. Environmental assessment using landscape analysis methodology: the case of the Jundiai Mirim river basin, Southeast Brazil. WIT Transactions on Ecology and the Environment, v.203, p.25-36, 2016. DOI: http://dx.doi.org/10.2495/EID160031

MILLIGAN, G. W.; COOPER, M. C.. A study of standardization of variables in cluster analysis. Journal of classification, v.5, n.2, p.181-204, 1988

PALM, C.; SANCHEZ, P.; AHAMED, S.; AWITI, A.. Soils: A contemporary perspective. Annu. Rev.Env.Resourc, v.32, p.99-129, 2007.

PULLEMAN, M.; CREAMER, R.; HAMER, U.; HELDER, J.; PELOSI, C.; PÉRÈS, G.; RUTGERS, M. Soil biodiversity, biological indicators and soil ecosystem services: an overview of European approaches. Current Opinion in Environmental Sustainability, v.4, p.529-538, 2012. DOI: https://doi.org/10.1016/j.cosust.2012.10.009

RIBEIRO, A. I.; PECHE FILHO, A.; MEDEIROS, G. A.; LONGO, R. M.; STORINO, M.; FENGLER, F. H.; KELLER, E. M. L.; RAPP, J. Z.; FREITAS, E. P.. Environmental diagnosis in areas with different use and occupation using the perception of diverse biological activity. WIT Transactionson Ecology and the Environment, v.162, p.129-136, 2012. DOI: http://dx.doi.org/10.2495/EID120121

ROSSI, M.. Mapa pedológico do Estado de São Paulo: revisado e ampliado. São Paulo: Instituto Florestal, 2017.

SANDHU, H. S.; WRATTEN, S. D.; CULLEN, R.; CASE, B.. The future of farming: The value of ecosystem services in conventional and organic arable land. An experimental approach. Ecological Economics, v.64, n.4, p.835-848, 2008. DOI: https://doi.org/10.1016/j.ecolecon.2007.05.007

SILVA, A. M.; SILVA, M. L. N.; CURI, N.; AVANZI, J. C.; FERREIRA, M. M.. Erosividade da chuva e erodibilidade de cambissolo e latossolo na região de lavras, sul de Minas Gerais. Revista Brasileira Ciências do Solo, v.33, p.1811$1820,2009$.

SILVA, I. R.; MENDONÇA, E. S.. Matéria orgânica do solo. In: NOVAIS, R. F.; ALVAREZ, V. H. V. ; BARROS, N. F. ; FONTES, R. L. ; CANTARUTTI, R. B. ; NEVES, J. C. L.. Fertilidade do solo. Viçosa: SBCS, 2007. p.275-374. DOI: http://dx.doi.org/10.1590/S0100-06832009000600029

SILVA, S. D. P.; FREITAS, H. R.; GONÇALVES-GERVÁSUI, R. C. R.; CARVALHO NETO, M. F.; MARINHO, C. M.. Agricultura Urbana e Periurbana: Dinâmica Socioprodutiva em Hortas Comunitárias De Petrolina/PE Semiárido Brasileiro. Nucleus, v.15, n.1, 2018. DOI:

https://doi.org/10.3738/1982.2278.2772

SOUZA, M. B.; GUSKE, A. C.. Agricultura urbana: um olhar a partir da agroecologia e da agricultura orgânica. COLóQUIO: Revista do Desenvolvimento Regional, Taquara, v.14, n.1, 2017. DOI: http://doi.org/10.26767/coloquio.v14i1.411

SOUZA, Z. M.; ALVES, M. C.. Movimento de água e resistência à penetração em um Latossolo Vermelho distrófico de cerrado, sob diferentes usos e manejos. Revista Brasileira de Engenharia Agrícola e Ambiental, v.7, n.1, p.18-23, 2003. DOI: http://doi.org/10.1590/S1415$\underline{43662003000100004}$

STOLF, R.; MURAKAMIJ, J. H.; BRUGNARO, C.; SILVA, L. G.; SILVA, L. C. F.; MARGARIDO, L. A. C.. Penetrômetro de impacto Stolf: programa computacional de dados em EXCELVBA. Revista Brasileira de Ciência do Solo, v.38, n.3, p.774782, 2014. DOI: https://doi.org/10.1590/S0100$\underline{06832014000300009}$

TAVARES FILHO, J.; BARBOSA, G. M. C.; GUIMARÃES, M. F.; FONSECA, I. C. B.. Resistência do solo à penetração $\mathrm{e}$ desenvolvimento do sistema radicular do milho (zeamays) sob diferentes sistemas de manejo em um Latossolo Roxo. Revista Brasileira de Ciência do Solo, v.25, n.3, 2001. DOI: https://doi.org/10.1590/S0100-06832001000300022

A CBPC - Companhia Brasileira de Produção Científica (CNPJ: 11.221.422/0001-03) detém os direitos materiais desta publicação. Os direitos referem-se à publicação do trabalho em qualquer parte do mundo, incluindo os direitos às renocões, expansões e disseminoc̃os da contribuiç̃o, bem como outros direitos subsidiários. Todos os trabalhos publicados eletronicamente poderão posteriormente ser publicados em coletâneas impressas sob coordenação da Sustenere Publishing da Companhia Brasileira de Produção Científica e seus parceiros autorizados. Os (as) autores (as) preservam os direitos autorais, mas não têm permissão para a publicação da contribuição em outro meio, impresso ou digital, em português ou em tradução. 